\title{
Two-level cervical disc arthroplasty versus anterior cervical discectomy and fusion: 10 -year outcomes of a prospective, randomized investigational device exemption clinical trial
}

\author{
Matthew F. Gornet, MD, ${ }^{1}$ Todd H. Lanman, MD, ${ }^{2}$ J. Kenneth Burkus, MD, ${ }^{3}$ Randall F. Dryer, MD, ${ }^{4}$ \\ Jeffrey R. McConnell, MD, ${ }^{5}$ Scott D. Hodges, DO, ${ }^{6}$ and Francine W. Schranck, BSN ${ }^{7}$
}

\begin{abstract}
${ }^{1}$ The Orthopedic Center of St. Louis, St. Louis, Missouri; ${ }^{2}$ Institute for Spinal Disorders, Cedars-Sinai Medical Center, Los Angeles, California; ${ }^{3}$ Wilderness Spine Services, Columbus, Georgia; ${ }^{4}$ Central Texas Spine Institute, Austin, Texas; ${ }^{5}$ Orthopedic Specialists, Allentown, Pennsylvania; ${ }^{6}$ Center for Sports Medicine \& Orthopaedics, Chattanooga, Tennessee; and ${ }^{7}$ SPIRITT Research, St. Louis, Missouri
\end{abstract}

\begin{abstract}
OBJECTIVE The authors assessed the 10-year clinical safety and effectiveness of cervical disc arthroplasty (CDA) to treat degenerative cervical spine disease at 2 adjacent levels compared to anterior cervical discectomy and fusion (ACDF).
\end{abstract}

METHODS A prospective, randomized, controlled, multicenter FDA-approved clinical trial was conducted comparing the low-profile titanium ceramic composite-based Prestige LP Cervical Disc $(n=209)$ at two levels with ACDF $(n=188)$. Ten-year follow-up data from a postapproval study were available on 148 CDA and 118 ACDF patients and are reported here. Clinical and radiographic evaluations were completed preoperatively, intraoperatively, and at regular postoperative follow-up intervals for up to 10 years. The primary endpoint was overall success, a composite variable that included key safety and efficacy considerations. Ten-year follow-up rates were $86.0 \%$ for CDA and $84.9 \%$ for ACDF.

RESULTS From 2 to 10 years, CDA demonstrated statistical superiority over ACDF for overall success, with rates at 10 years of $80.4 \%$ versus $62.2 \%$, respectively (posterior probability of superiority [PPS] $=99.9 \%$ ). Neck Disability Index (NDI) success was also superior, with rates at 10 years of $88.4 \%$ versus $76.5 \%$ (PPS $=99.5 \%$ ), as was neurological success $(92.6 \%$ vs $86.1 \%$; PPS $=95.6 \%)$. Improvements from preoperative results in NDI and neck pain scores were consistently statistically superior for CDA compared to ACDF. All other study effectiveness measures were at least noninferior for CDA compared to ACDF through the 10-year follow-up period, including disc height. Mean angular ranges of motion at treated levels were maintained in the CDA group for up to 10 years. The rates of grade IV heterotopic ossification (HO) at the superior and inferior levels were $8.2 \%$ and $10.3 \%$, respectively. The rate of severe $\mathrm{HO}$ (grade III or IV) did not increase significantly from 7 years $(42.4 \%)$ to 10 years (39.0\%). The CDA group had fewer serious (grade 3-4) implantrelated or implant/surgical procedure-related adverse events $(3.8 \%$ vs $8.1 \%$; posterior mean $95 \%$ Bayesian credible interval $[\mathrm{BCl}]$ of the log hazard ratio $[\mathrm{LHR}]-0.92[-1.88,-0.01])$. The CDA group also had statistically fewer secondary surgical procedures at the index levels (4.7\%) than the ACDF group (17.6\%) (LHR [95\% BCI] $-1.39[-2.15,-0.61])$ as well as at adjacent levels ( $9.0 \%$ vs $17.9 \%)$.

CONCLUSIONS The Prestige LP Cervical Disc, implanted at two adjacent levels, maintains improved clinical outcomes and segmental motion 10 years after surgery and is a safe and effective alternative to fusion.

Clinical trial registration no.: NCT00637156 (clinicaltrials.gov)

https://thejns.org/doi/abs/10.3171/2019.4.SPINE19157

KEYWORDS cervical degenerative disc disease; cervical disc arthroplasty; Prestige LP disc replacement; artificial cervical disc; radiculopathy; myelopathy; two-level disc disease; anterior cervical discectomy and fusion; ACDF

ABBREVIATIONS ACDF = anterior cervical discectomy and fusion; $\mathrm{AE}=$ adverse event; $\mathrm{BCl}=$ Bayesian credible interval; $\mathrm{CDA}=\mathrm{cervical}$ disc arthroplasty; $\mathrm{cTDR}=$ cervical TDR; DDD = degenerative disc disease; FSU = functional spinal unit; HO = heterotopic ossification; HPD = highest posterior density; IDE = investigational device exemption; LHR = log hazard ratio; MCS = Mental Component Summary of SF-36; NDI = Neck Disability Index; PAS = postapproval study; PCS = Physical Component Summary of SF-36; PPS = posterior probability of superiority; ROM = range of motion; TDR = total disc replacement.

SUBMITTED February 9, 2019. ACCEPTED April 9, 2019.

INCLUDE WHEN CITING Published online June 21, 2019; DOI: 10.3171/2019.4.SPINE19157. 
A LTHOUGH anterior cervical discectomy and fusion (ACDF) is the standard surgical treatment for cervical degenerative disc disease (DDD) associated with radiculopathy and myelopathy, clinical studies have demonstrated the safety and efficacy of total cervical disc replacements, variously referred to as total disc replacement (TDR), cervical total disc replacement (cTDR), cervical disc replacement (CDR), cervical disc arthroplasty (CDA), and artificial disc replacement (ADR), for both one- and two-level disease. ${ }^{2-5,7,10-12,15,20,21,24,25,27}$ These studies used ACDF as the control group/standard treatment against which to assess noninferiority and potential superiority of CDA.

ACDF affects segmental motion at adjacent vertebrae, altering spinal biomechanics and creating abnormal loads, ${ }^{6,32}$ which may place additional stress on adjacent discs that could accelerate their degeneration. 9,26,32 Many patients have multilevel disease, and two-level ACDF may result in even greater stresses to adjacent discs. ${ }^{17}$ Multilevel ACDF also has higher rates of pseudarthrosis, revisions, complications, and reoperations than single-level $\mathrm{ACDF}^{28,30} \mathrm{CDA}$ was designed as a motion-preserving alternative to ACDF for treating DDD at one or more levels.

The Prestige LP Cervical Disc (Medtronic, Inc.) was approved by the FDA in 2014 for treating single-level DDD and intractable radiculopathy or myelopathy. ${ }^{10} \mathrm{~A}$ clinical trial began in 2006 to evaluate the safety and efficacy of Prestige LP at two adjacent levels compared to ACDF. The primary outcome measure was overall success 24 months following surgery. Overall success rates were $81.4 \%$ and $69.4 \%$ for the CDA and ACDF groups, respectively. ${ }^{11}$ Both noninferiority and superiority in overall success were established for CDA compared to ACDF, and the FDA granted marketing approval for the use of the Prestige LP Cervical Disc in the treatment of two-level degenerative disc disease with intractable radiculopathy and/ or myelopathy in 2016. A postapproval study (PAS) with patient follow-up to 10 years was required by the FDA, and 7-year follow-up results have been reported..$^{15}$ Those results continued to show the noninferiority of CDA compared to $\mathrm{ACDF}$ as well as superiority in overall success and other measures.

This report assesses long-term effectiveness and safety of the Prestige LP Cervical Disc at two contiguous levels, comparing outcomes at 10 years postoperatively to those for ACDF. To our knowledge, this is the first randomized study with 10-year follow-up data for a two-level use of a spinal device.

\section{Methods}

Surgeries for this clinical trial occurred between June 2006 and November 2007 (clinicaltrials.gov, NCT00637156). The study protocol and informed consent form received IRB approval (Western Investigational Review Board, protocol no. 20060636, study no. 1078218). The prospective, randomized, multicenter, controlled study was designed to assess the safety and efficacy of two-level cervical disc arthroplasty with the Prestige LP Cervical Disc compared with the control treatment (a twolevel anterior cervical fusion procedure involving cortical ring allograft and the ATLANTIS Cervical Plate System, Medtronic, Inc.) in patients with intractable radiculopathy and/or myelopathy at two adjacent levels of the cervical spine. Informed consent was obtained from all patients. The specific methods and procedures for this clinical trial have been described in detail elsewhere, including inclusion and exclusion criteria and detailed definitions of all outcome measures. ${ }^{11,15}$ Key components of the research protocol are summarized below.

\section{Patients}

Patients were randomized to receive either Prestige LP CDA or the fusion control treatment. In total, 397 patients (209 CDA and 188 ACDF) were treated with the assigned treatment. Characteristics of the CDA patients included mean (SD) age of 47.1 (8.3) years, $56.0 \%$ female, and $93.3 \%$ Caucasian. The treatment groups were similar demographically, with no statistical differences $(p \geq 0.05)$ except preoperative work status (not considered a clinically important difference). ${ }^{11}$ The groups did not differ in relevant preoperative medical conditions or medication usage, including time from symptom onset to surgery, previous neck surgery, or pain medication usage. Radiculopathy was the presenting complaint in $71.8 \%$ and $72.9 \%$ of the CDA and ACDF groups, respectively, with another 25.8\% and $23.9 \%$, respectively, presenting with both radiculopathy and myelopathy. Finally, there were no significant preoperative differences between groups in any of the clinical measures. Treatment levels were C5-6 or C6-7 in 78\% of CDA and $75 \%$ of ACDF patients.

At 10 years postoperatively, 148 patients in the CDA group and 118 in the ACDF group had evaluations (Table 1), yielding follow-up rates of $86.0 \%$ for CDA and $84.9 \%$ for ACDF after excluding patients at sites not participating in the PAS study, deaths, and withdrawals. Nearly all withdrawals were initiated by patients after surgery, most commonly because they found the study requirements too demanding (e.g., too much time, too many visits), they were feeling better and did not feel they needed to see the doctor, or they were moving from the area. For patients lost to follow-up over time, the most frequent reasons were lack of contact information after moving out of the area or unwillingness to undergo further evaluations; some patients died. Patient demographics and preoperative medical status and medication usage were compared between groups for just patients included in this 10-year follow-up study. No significant differences were found. The mean patient age preoperatively was 47.1 years for CDA patients and 47.6 years for ACDF patients.

\section{Materials \\ Investigational Device}

The Prestige LP Cervical Disc is a dynamic device made of a titanium alloy/titanium carbide composite (also referred to as titanium ceramic composite). It contains small amounts of vanadium and aluminum and does not contain nickel or chrome. It is implanted through an anterior approach following a discectomy and is available in various sizes to accommodate the intervertebral disc space and to engage adjacent vertebral bodies. Device components are 
TABLE 1. Patient accountability for long-term follow-up

\begin{tabular}{|c|c|c|c|c|c|c|}
\hline \multirow[b]{2}{*}{ Patient Status } & \multicolumn{2}{|c|}{5 Yrs } & \multicolumn{2}{|c|}{7 Yrs } & \multicolumn{2}{|c|}{10 Yrs } \\
\hline & $\mathrm{CDA}$ & ACDF & CDA & ACDF & CDA & ACDF \\
\hline Enrolled & 209 & 188 & 209 & 188 & 209 & 188 \\
\hline At sites not participating at $10 \mathrm{yrs}$ & 0 & 0 & 0 & 0 & 28 & $28^{*}$ \\
\hline Theoretical follow-up & 209 & 188 & 209 & 188 & 181 & 160 \\
\hline Cumulative withdrawals & 5 & 12 & 6 & 14 & 7 & 18 \\
\hline Cumulative deaths & 1 & 1 & 2 & 2 & 2 & 3 \\
\hline Patients to be expected & 203 & 175 & 201 & 172 & 172 & $139^{*}$ \\
\hline Evaluated expected patients & 167 & 140 & 154 & 127 & 148 & $118^{*}$ \\
\hline Follow-up (\%) & 82.3 & 80.0 & 76.6 & 73.8 & 86.0 & 84.9 \\
\hline
\end{tabular}

Values are presented as number of patients unless otherwise indicated.

* One ACDF patient who was at one of the nonparticipating sites, and thus was not included in the numbers of expected or evaluated patients, had a serious implant-related $A E$ at 6 weeks postoperatively and by definition the results for this patient were considered a failure for overall success at all subsequent time points. Therefore, there were 119 patients in total who had overall success results at 10 years.

placed into the vertebral bodies through impaction at surgery and maintained via bony ingrowth over time.

\section{Outcome Measures}

The primary endpoint was "overall success," a composite of safety and efficacy endpoints. Overall success was achieved if the postoperative score improvement in the Neck Disability Index (NDI) ${ }^{31}$ was $\geq 15$ points, neurological status did not worsen, and no serious implant-associated or implant/surgical procedure-associated adverse event (AE), or second surgery, which was deemed "failure," occurred. Definitions of "success" for individual efficacy measures have been previously described. ${ }^{15}$

Other outcome measures included neck and arm pain numerical rating scales adapted from a previously defined scale,,$^{18}$ yielding a total pain score based on both intensity and frequency; the Medical Outcomes Study SF-36 ${ }^{33}$ Physical Component Summary (PCS) and Mental Component Summary (MCS); radiographic assessments of 3 types (disc height assessed using functional spinal units [FSUs], heterotopic ossification [HO] assessed only in the CDA group and graded from 0 to IV according to the method reported by Mehren et al., ${ }^{19}$ and implant condition); patient satisfaction (3 questions answered numerically with a 5-point scale from "definitely true" to "definitely false"); patient global perceived effect (7-point scale from "completely recovered" to "vastly worsened"); foraminal compression test; physician's perception of results ("excellent," "good," "fair," or "poor"); AE including severity (grades 1-4) and possible association with implant and/or surgical procedure assessed by an independent Clinical Adjudication Committee; neurological status; and secondary surgical procedures classified as revision, removal, supplemental fixation, reoperation, or other. A secondary surgical procedure at the index level(s) caused the patient's surgical outcome to be classified as a study failure with respect to overall success if it required supplemental fixation, implant removal, or revision.

\section{Procedures}

Patient evaluations occurred preoperatively (within 6 months of surgery), at surgery, and postoperatively at approximately 6 weeks, 3 months, 6 months, and 1, 2, 3, 5, 7, and 10 years. The clinical trial endpoint for the investigational device exemption (IDE) study was 24 months, but PAS follow-ups have continued, and the 10-year findings are the subject of this report.

\section{Radiographic Measurements}

Images obtained at study sites were sent to a central core laboratory (Biomedical Systems, St. Louis, MO) for independent review by two primary reviewers using a proprietary imaging archival system and software-based measurement tools for quantitative measurements (e.g., intervertebral angle, horizontal translation, FSU height, etc.). A third reviewer was used for adjudications.

\section{Statistical Methods}

The primary objective of the IDE study was to demonstrate that the overall success rate in the CDA group was statistically noninferior to the overall success rate in the ACDF group at 24 months following surgery, with a prespecified noninferiority margin of 0.10 (i.e., a minimum clinically important difference in success rate of 10\%). If noninferiority in overall success was established for CDA compared to ACDF, the CDA treatment was considered to be safe and effective, and then superiority was evaluated. Success rates for individual effectiveness endpoints were compared between the two treatment groups; when noninferiority of CDA was established, superiority was evaluated. This same analysis strategy was used for the PAS evaluations, including the 10 -year results presented here.

Bayesian statistical methods were used for comparing differences in success rates between groups. The criterion for noninferiority and for superiority of CDA compared to ACDF was a posterior probability of at least $95 \%$. Because noninferiority for overall success and individual endpoints was, in fact, established, only posterior probability of superiority (PPS) results are presented here. Improvements from preoperative results in continuous measures such as NDI scores, SF-36 scores, and neck and arm pain scores 
were also compared between treatment groups by using Bayesian methods.

For all adverse events and secondary surgical procedures, including secondary surgeries involved with adjacent level(s), usual hypotheses were used to assess statistical differences between treatment groups. Log hazard ratios (LHRs) of rates of occurrence between groups and the 95\% Bayesian credible interval (BCI) of highest posterior density (HPD) were computed to determine whether rates differed statistically between groups. Noninformative priors were used for all Bayesian analyses.

For patients who had additional ("secondary") surgical procedures/interventions (supplemental fixation, implant removal, or revision), their results were deemed failures for overall success. Because these additional surgical procedures/interventions had potential to alter the original study treatment outcomes, for all neurological status and individual effectiveness variables the last observation obtained before additional surgery was carried forward for subsequent observation periods.

An independent statistical analysis using the same protocol approved by the FDA was performed for the 24-month and 60-month data by the Vanderbilt University Medical Center Biostatistics Collaboration Center. Results for both intervals were consistent with the sponsor Medtronic's analyses and thus independent analyses were not performed for other intervals and were not required by FDA.

\section{Results \\ Efficacy Success Rates}

Figure 1 shows success rates and posterior probabilities of superiority for overall success, NDI success, and neurological success over time. Superiority was established for CDA compared to ACDF for overall success and NDI success at all postoperative intervals. Observed overall success rates for $\mathrm{CDA}$ and $\mathrm{ACDF}$ at 10 years were $80.4 \%$ and $62.2 \%$, respectively (PPS $=99.9 \%$ ), yielding a difference in Bayesian success probabilities (95\% BCI) between CDA and ACDF of 18.0\% (7.3\%, 28.7\%). At 10 years, $88.4 \%$ of CDA patients met criteria for NDI success compared to $76.5 \%$ of ACDF patients (PPS $=99.5 \%$ ), with a difference in Bayesian success probabilities (95\% BCI) of $11.9 \%(2.7 \%, 21.3 \%)$. Neurological success rates tended to be higher for CDA over time and were statistically superior at 7 and 10 years compared to ACDF. At 10 years, the neurological success rate was $92.6 \%$ for CDA compared to $86.1 \%$ for $\mathrm{ACDF}(\mathrm{PPS}=95.6 \%)$.

\section{Individual Effectiveness Variables}

Observed mean scores over time for some individual effectiveness variables, including NDI, neck pain, arm pain, and SF-36 PCS, are shown in Fig. 2. In both groups the results showed significant improvement over preoperative results for all of these measures (all $\mathrm{p} \leq 0.001$ ), with CDA showing superiority at all intervals for improvements in NDI score (PPS $=99.9 \%$ at 10 years) and neck pain score (PPS $=$ approximately $100.0 \%$ at 10 years). Mean improvements from preoperative results in arm pain score and SF36 PCS were numerically better for CDA than ACDF at all long-term intervals, but did not consistently show statistical superiority.

\section{Radiographic Measurements}

Disc (FSU) height was maintained in both groups. FSU success was defined as a $\leq 2-\mathrm{mm}$ decrease either anteriorly or posteriorly from 6 weeks postoperatively. There were no statistical differences in FSU success between treatment groups for any long-term follow-up interval. FSU success rates at 10 years were $93.3 \%$ and $91.6 \%$ for CDA and ACDF, respectively (Fig. 3A). Angular range of motion (ROM) values at superior and inferior target levels on average were maintained in the CDA group, with no statistically significant changes from the preoperative to 10 -year results (Fig. 3B). Fusion success rates for the ACDF group at 10 years were $95.2 \%$ at the superior level, $97.9 \%$ at the inferior level, and $93.8 \%$ overall. Five of the 6 patients with fusion failures had undergone secondary surgeries before the 10 -year evaluation.

\section{Patient and Physician Perceptions}

At 10 years postoperatively, $93.2 \%$ of CDA and $92.2 \%$ of ACDF patients reported that they were "definitely" or "mostly" satisfied; $92.5 \%$ and $87.8 \%$, respectively, said they were helped as much as expected; and $93.2 \%$ and $87.8 \%$, respectively, said they would have the surgery again for the same condition. Patients rated the perceived effect of their surgical treatment from "completely recovered" to "vastly worsened." At 10 years, $95.9 \%$ of the CDA group and $93.9 \%$ of the ACDF group perceived their result as at least improved. The rates of physician perceptions of results as successful based on a nonvalidated questionnaire were $98.0 \%$ and $80.0 \%$ for the two treatments, respectively.

\section{Safety}

Table 2 summarizes cumulative rates (life-table estimations) of any type of AE through 10 years postoperatively and comparisons between treatment groups by time-toevent analysis. The CDA group had a statistically lower rate of any type of serious $\mathrm{AE}$ and a lower rate of possibly implant- or implant/procedure-related serious AEs. Cumulative rates of serious AEs (grade 3 or 4 ) that were classified as associated with implant or implant/surgical procedure were $3.8 \%$ in CDA and $8.1 \%$ in ACDF patients through 10 years postoperatively (LHR [95\% BCI] -0.92 $[-1.88,-0.01])$, and the prevalence of specific serious implant or implant/surgical procedure-associated adverse events is detailed in Table 3 .

The cumulative rates of any secondary surgery at treated levels through 10 years (Table 2) were $4.7 \%$ and $17.6 \%$ for the CDA and ACDF groups, respectively, a statistically significant difference (LHR [95\% BCI] -1.39 [-2.15, -0.61]) favoring CDA. In CDA patients, the 6 removals all occurred prior to the 5-year follow-up and have been previously described.${ }^{15}$ In the ACDF group, "elective removals" occurred in 9 patients and were typically performed at the discretion of the investigator while performing a surgical procedure on adjacent or other cervical levels requiring removal of the plate and placement of a new plate. If we 


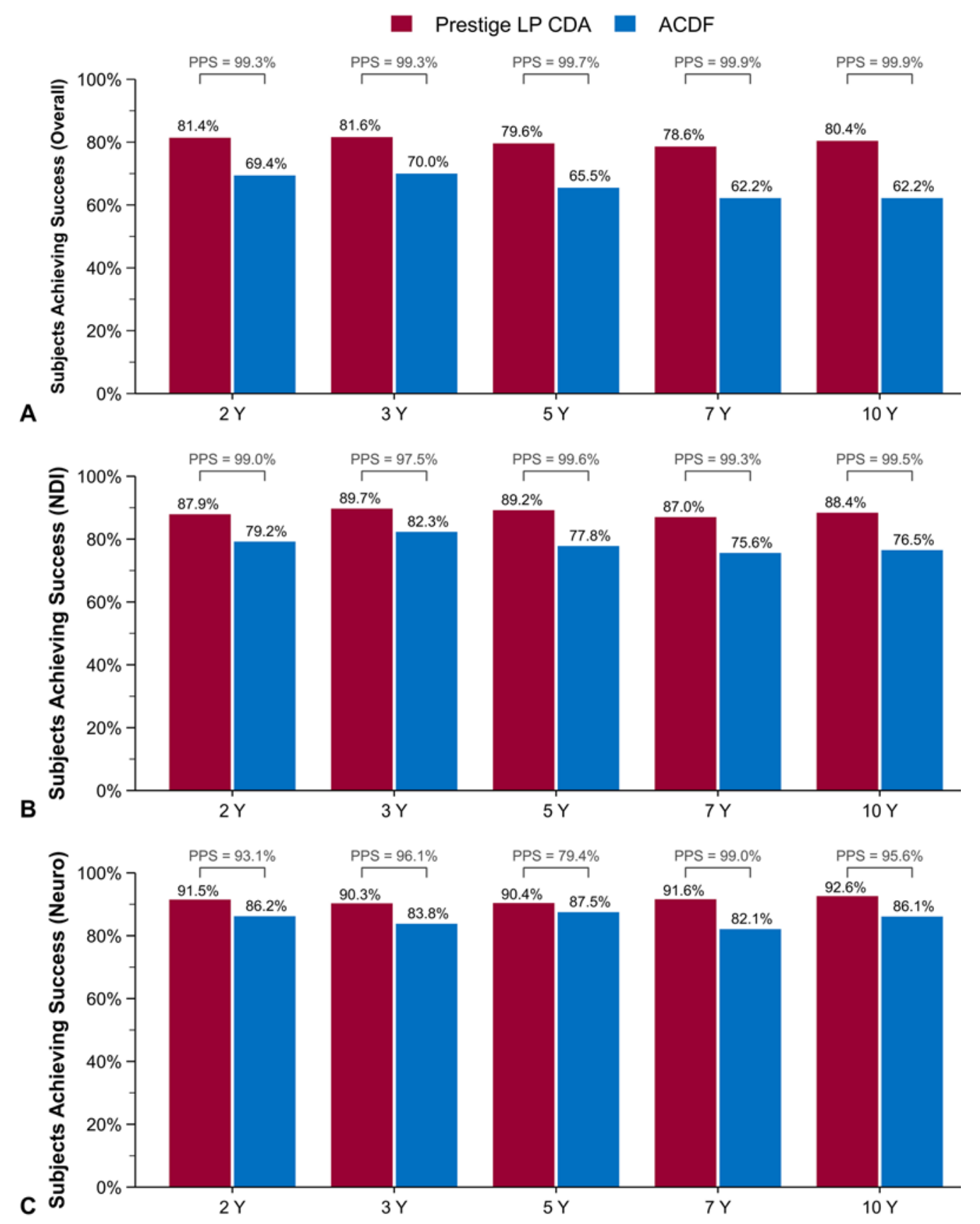

FIG. 1. Success rates over time for both the CDA and ACDF groups for the efficacy measures overall success (A), NDI success (B), and neurological success (C). PPS $>95 \%$ considered statistically superior. $Y=$ years.

exclude the 9 elective removals in the ACDF group from the statistical comparison, the rate of secondary surgeries at index levels in the ACDF group (11.8\% cumulative) is still statistically greater than that for the CDA group (LHR [95\% BCI $]-1.00[-1.85,-0.22])$.

Cumulative rates of second surgeries involving adjacent levels through 10 years were $9.0 \%$ and $17.9 \%$ for CDA and ACDF, respectively, a statistically significant difference (LHR [95\% BCI] $-0.66[-1.29,-0.01]$ ) in favor of CDA (Table 2). Figure 4 shows the Kaplan-Meier curves for time to secondary surgeries at adjacent levels, indicating the consistently lower rate in the CDA group over time, which was statistically different by 10 years postoperatively (PPS $=98.0 \%)$.

Grading of heterotopic ossification (HO) was assessed by independent radiologists. The presence of any grade III or IV HO in the CDA group over time is summarized in Table 4. Although no serious HO AEs that were classified as likely to be implant related or clinically significant were reported by any investigators as part of their AE documentation (Table 3), there was radiographic evidence, reported separately by the independent radiologist reviewers, of grade IV HO at the superior (8.2\%) and inferior (10.3\%) treatment levels. The rate of $\mathrm{HO}$ of either grade III or IV 

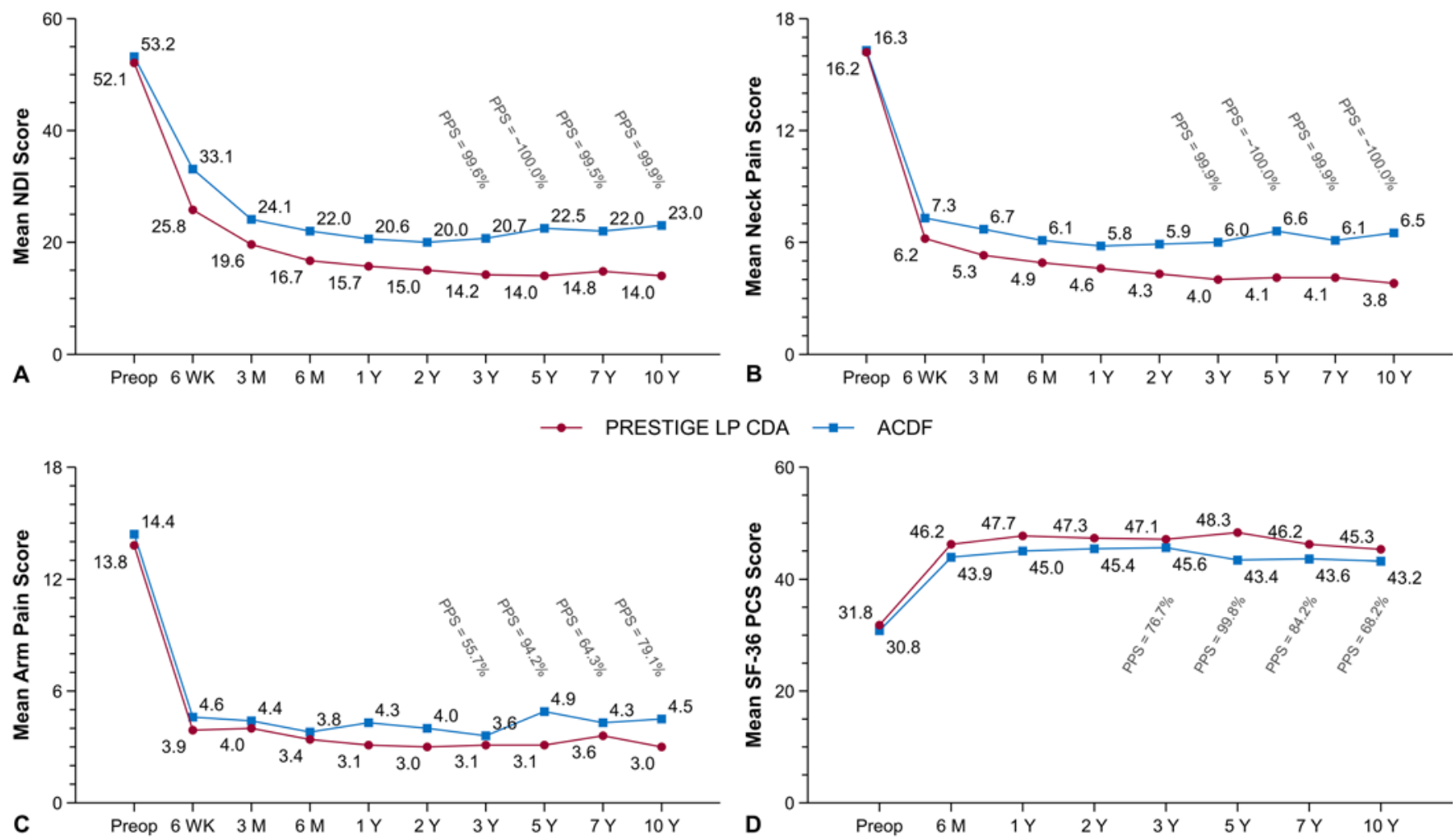

FIG. 2. Mean scores over time for both the CDA and ACDF groups for efficacy measures NDI score (A), neck pain score (B), arm pain score (C), and SF-36 PCS score (D). For NDI, neck pain, and arm pain, a lower score indicates less disability or pain. For SF36 PCS, a higher score means better functioning. PPS based on the between-treatment comparisons of score improvements from preoperative; PPS > 95\% considered statistically superior. $\mathrm{M}=$ months; $\mathrm{WK}=$ weeks.

at either or both levels was $39.0 \%$ at 10 years postoperatively, not an increase from 7 years (42.4\%). An additional analysis compared overall success rates at each follow-up interval, including 10 years, between those with severe $\mathrm{HO}$ (grade III or IV) and those with nonsevere HO (grades 0 II) as measured at 2 and at 10 years (data not shown). There was no statistically significant difference in overall success rates between the HO severity subgroups at any follow-up interval.

\section{Discussion}

This long-term follow-up study continues to show the noninferiority of the Prestige LP Cervical Disc compared to ACDF at two levels for symptomatic cervical DDD. At 10 years postoperatively, $\mathrm{CDA}$ was noninferior compared to ACDF on all effectiveness outcome measures. The CDA group had statistically superior results compared to ACDF in overall success rate $(80.4 \%$ vs $62.2 \%)$, NDI success $(88.4 \%$ vs $76.5 \%)$, and neurological success $(92.6 \%$ vs $86.1 \%)$. FSU height was maintained in both groups. The rate of clinically significant AEs (grade 3 or 4 ) that were considered to possibly be associated with the implant or implant/surgical procedure were significantly lower in the CDA group (3.8\% vs $8.1 \%$ ), as was the rate of secondary surgeries $(4.7 \%$ vs $17.6 \%)$. Finally, rates of secondary surgery involving an adjacent level up to 10 years after the clinical study treatment were significantly lower in the
CDA group than the ACDF group $(9.0 \%$ vs $17.9 \%$, respectively).

Presently, at least 7 CDA devices in the US have received FDA approval at either one or two cervical levels. Long-term results (4-7 years postoperatively) have been published on several of these devices, primarily for singlelevel treatment. ${ }^{2,7,15,24,25,29}$ One 10-year single-level study has also been reported. ${ }^{16}$ These studies consistently show noninferiority of CDA compared to ACDF, and most show superiority in overall success rates, lower rates of secondary surgeries, and low rates of serious AEs.

There have been a number of reviews and meta-analyses of the CDA literature. Nunley et al. recently summarized the current state of evidence both in and outside the US regarding cervical disc arthroplasty. ${ }^{23}$ They note that the US literature, consisting of predominantly level I evidence from FDA-approved clinical trials, supports the use of cTDR at one and two surgical levels in comparison to ACDF. They further conclude that the "volume of level I and II evidence supporting the efficacy of cTDR is unparalleled in the field of spine surgery." Badve et al., reviewing the literature on one-level devices in an "expert review," also concluded that CDA resulted in favorable rates of long-term functional recovery, AEs, development of adjacent segment degeneration, and secondary surgeries in comparison to ACDF. ${ }^{1}$ Both Nunley et al. and Badve et al. provide extensive referencing of the literature on CDA versus $\mathrm{ACDF}$ and related topics. 


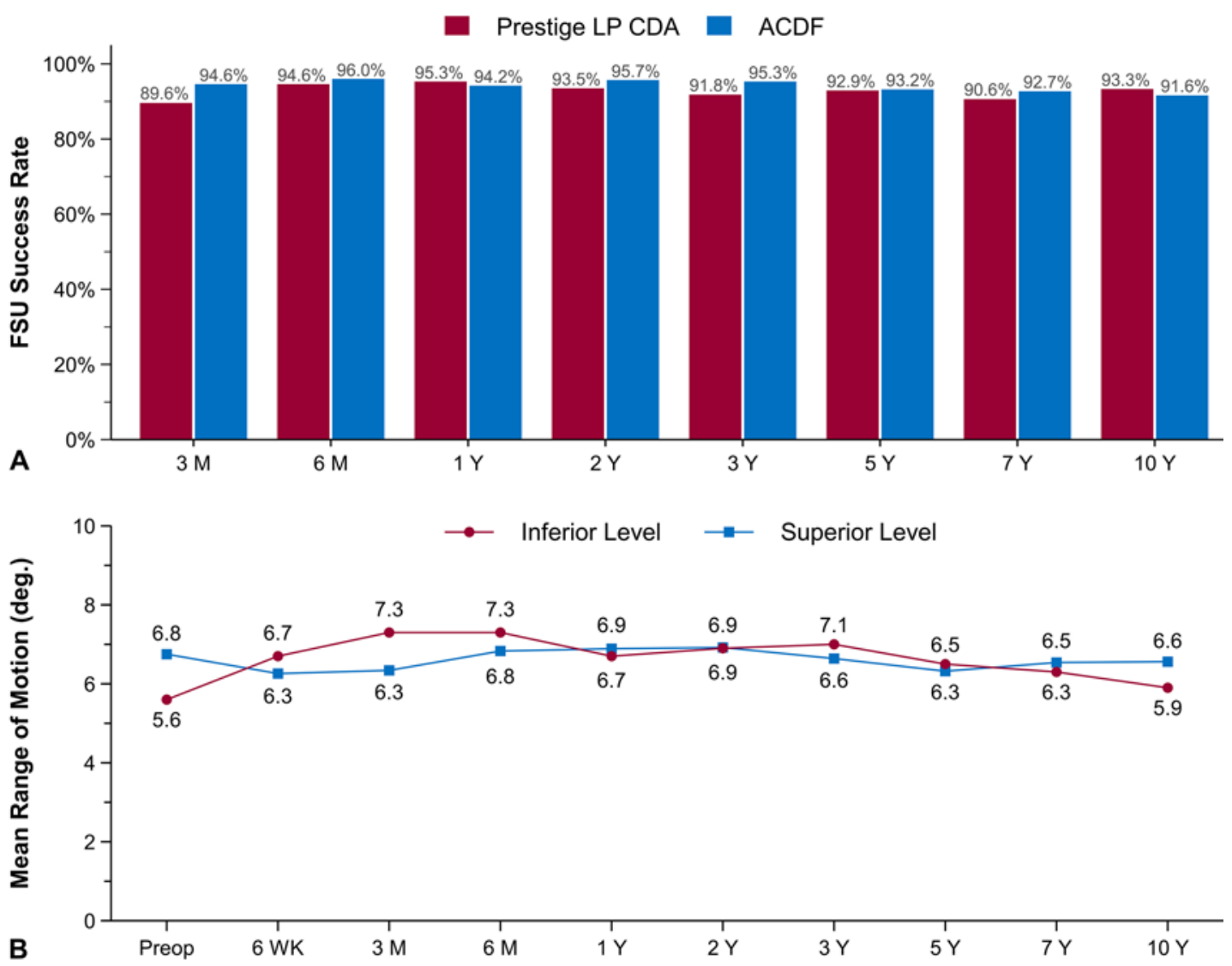

FIG. 3. Radiographic outcomes. FSU success rates for the CDA and ACDF groups over time (A), with no statistical difference at any point of long-term follow-ups, and mean ROM over time at superior and inferior levels of the CDA patients (B). deg. $=$ degrees.

TABLE 2. Patients who reported AEs and who underwent secondary surgeries through 10 years postoperatively, based on the life-table estimation

\begin{tabular}{|c|c|c|c|}
\hline AE Type* & $\begin{array}{c}C D A, \\
n=209\end{array}$ & $\begin{array}{c}\text { ACDF } \\
n=188\end{array}$ & LHR, Posterior Mean (95\% BCl) $\dagger$ \\
\hline \multicolumn{4}{|l|}{$\mathrm{AE}$} \\
\hline At least 1 of any AE type & $206(99.1 \%)$ & $179(97.3 \%)$ & $0.02(-0.18,0.23) \ddagger$ \\
\hline Any serious $A E$ & $124(66.7 \%)$ & $120(70.9 \%)$ & $-0.31(-0.57,-0.06) \S$ \\
\hline Possibly implant- or implant/procedure-related AEף & $55(31.7 \%)$ & $44(25.0 \%)$ & $0.04(-0.35,0.45) \ddagger$ \\
\hline Serious, possibly implant- or implant/procedure-related AE & $7(3.8 \%)$ & $14(8.1 \%)$ & $-0.92(-1.88,-0.01) \S$ \\
\hline \multicolumn{4}{|l|}{ Secondary surgery } \\
\hline Secondary surgery at either index level ${ }^{* *}$ & $9(4.7 \%)$ & $27(17.6 \%)$ & $-1.39(-2.15,-0.61) \S$ \\
\hline Revision & $0(0.0 \%)$ & $2(1.4 \%)$ & $-798.11(-1956.24,0.60) \ddagger$ \\
\hline Removal & $6(3.1 \%)$ & $7(4.1 \%)$ & $-0.35(-1.48,0.80) \ddagger$ \\
\hline Elective removal & $0(0.0 \%)$ & $9(6.4 \%)$ & $-802.74(-1959.04,-1.53)$ \\
\hline Supplemental fixation & $2(1.2 \%)$ & $8(5.4 \%)$ & $-1.81(-3.58,-0.17)$ \\
\hline Reoperation & $3(1.6 \%)$ & $5(3.0 \%)$ & $-0.78(-2.32,0.75) \ddagger$ \\
\hline Supplemental fixation w/ bone growth stimulator & $0(0.0 \%)$ & $5(2.8 \%)$ & $-799.85(-1961.63,-1.23)$ \\
\hline Secondary surgery involving adjacent level(s) ${ }^{* *}$ & $16(9.0 \%)$ & $24(17.9 \%)$ & $-0.66(-1.29,-0.01) \S$ \\
\hline \multicolumn{4}{|c|}{$\begin{array}{l}\text { Values are presented as number of patients (cumulative percentage) unless otherwise indicated. } \\
\text { *WHO grade } 3 \text { or } 4 \text { AEs considered serious. } \\
\text { † BCI in the HPD. } \\
\text { † Not statistically different. } \\
\text { § CDA statistically less frequent than ACDF over the time period. } \\
\text { I AE deemed to be associated with device or device/surgical procedure. } \\
\text { ** Some patients had more than one secondary surgery; some secondary surgeries involved both }\end{array}$} \\
\hline
\end{tabular}


TABLE 3. Patients with grade 3 or 4 implant- or implant/surgical procedure-related AEs through 10 years, based on the life-table estimation

\begin{tabular}{lccc}
\hline & CDA & ACDF & LHR, Posterior Mean $\left(95 \%\right.$ BCI ${ }^{*}$ \\
\hline Grade 3 or 4 AEs & $7(3.8)$ & $14(8.1)$ & $-0.92(-1.88,-0.01)$ \\
\hline Dysphagia/dysphonia & $1(0.6)$ & $1(0.7)$ & $-0.23(-3.90,3.35) \dagger$ \\
\hline HO & $0(0.0)$ & $3(1.6)$ & $-798.33(-1957.40,-0.77) \dagger$ \\
\hline Implant events & $2(1.0)$ & $3(1.6)$ & $-0.66(-2.70,1.32) \dagger$ \\
\hline Neck \&/or arm pain & $3(1.7)$ & $7(4.6)$ & $-1.16(-2.63,0.27) \dagger$ \\
\hline Neurological & $1(0.7)$ & $2(1.2)$ & $-1.18(-4.23,1.67) \dagger$ \\
\hline Nonunion & $0(0.0)$ & $9(5.0)$ & $-800.60(-1967.56,-1.75)$ \\
\hline Other & $1(0.5)$ & $0(0.0)$ & $797.35(-1.52,1961.63) \dagger$ \\
\hline Other pain & $1(0.5)$ & $2(1.6)$ & $-1.20(-4.28,1.60) \dagger$ \\
\hline Spinal event & $4(2.0)$ & $5(2.7)$ & $-0.41(-1.82,0.97) \dagger$ \\
\hline Trauma & $0(0.0)$ & $1(0.6)$ & $797.62(-1958.28,1.34) \dagger$ \\
\hline Vascular & $1(0.5)$ & $0(0.0)$ & $-795.68(-1.52,1961.63) \dagger$ \\
\hline Wound (noninfectious) & $0(0.0)$ & $1(0.5)$ & \\
\hline
\end{tabular}

Values are presented as number of patients (cumulative percentage) unless otherwise indicated.

${ }^{*} \mathrm{BCl}$ in the HPD.

$\dagger$ Not statistically different.

Recent meta-analyses that compare CDA to ACDF are based on the large amount of published clinical trial data now available, although few focus specifically on two-level studies. ${ }^{14,34-36,38}$ One meta-analysis included 19 randomized controlled trials involving 4516 cases, the majority single level, with short- and midterm follow-up, and demonstrated better outcomes for CDA than ACDF on a wide variety of measures. ${ }^{38} \mathrm{~A}$ number of other more recent meta-analyses have reported advantages to CDA. Xu et al. provided what they termed an "indirect" meta-analysis using data from 5343 patients in which they estimated the relative effectiveness of each type of 4 different CDA and ACDF procedures, and these authors concluded that any of the total cervical replacement devices were good choices for improving functional outcomes and reducing secondary surgeries in comparison to ACDF. ${ }^{36}$

One meta-analysis compared outcomes for patients undergoing single-level versus multilevel TDR and found the outcomes were equally favorable, ${ }^{39}$ as did a recent individual study. ${ }^{2}$ Similar to the current study, clinical trials

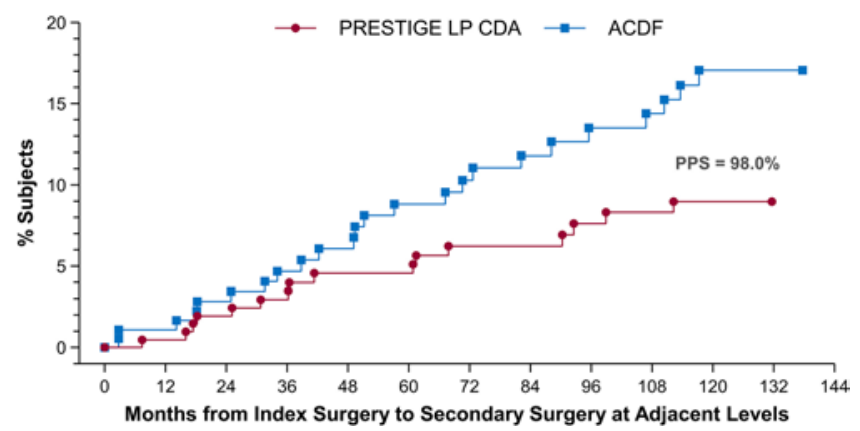

FIG. 4. Rates of secondary surgeries involved with adjacent levels over time for the CDA and ACDF groups. PPS > 95\% considered statistically superior. of other cervical prostheses have also found that outcomes after two-level CDA were superior to outcomes after twolevel ACDF, including in patients with follow-up through 7 years. . $^{2,24,25}$

One potential advantage of CDA compared to ACDF relates to the additional stress that ACDF may place on adjacent discs, possibly resulting in accelerated degeneration of those discs, and the finding that this problem may be increased in multilevel disease. Our study found that CDA patients showed a statistically lower cumulative rate of need for secondary surgeries than ACDF patients through 10 years postoperatively for both the index $(4.7 \%$ vs $17.6 \%$, respectively) and adjacent (9.0\% vs $17.9 \%$, respectively) levels. Figure 4 shows that the cumulative rate increases in secondary surgeries involving adjacent levels appears to be linear over time, with differences between CDA and ACDF becoming larger as time went on, approximately $0.9 \%$ per year for CDA and $1.8 \%$ per year for ACDF in this two-level study. Similar findings have been reported for other CDA devices used at two levels. ${ }^{13}$ One recent meta-analysis also specifically addressed this issue, finding that there was a significantly lower rate of adjacent segment degeneration or disease and a lower reoperation rate in TDR compared to ACDF, and that the superiority of TDR tended to increase across time. ${ }^{37}$

One concern with CDA is the possibility of significant $\mathrm{HO}$. In the current study, rates of grade IV $\mathrm{HO}$ at 10 years postoperatively were $8.2 \%$ at the superior level and $10.3 \%$ at the inferior level, with an overall rate of $39 \%$ grade III or IV at either or both levels. The rates of patients with grade III or IV HO did not increase from 7 years (42.4\%) to 10 years (39.0\%). In fact, those rates appeared to be quite stable at 5, 7, and 10 years postoperatively. These findings are similar to those reported by Nunley et al. of combined total grades III or IV at both levels of $37.4 \%$ for two-level CDA with a different CDA device at 7 years postoperatively. ${ }^{22}$ Nunley et al. did find a significant negative cor- 
TABLE 4. Percentages of patients with grade III or IV HO for superior and inferior levels over time for the CDA group

\begin{tabular}{cccc}
\hline $\begin{array}{c}\text { HO Severity at } \\
\text { Follow-Up }\end{array}$ & Superior Level & Inferior Level & $\begin{array}{c}\text { Either or Both } \\
\text { Levels }\end{array}$ \\
\hline 3 yrs $(n=184)$ & & & \\
\hline Grade III & $14.1 \%$ & $21.2 \%$ & $7.6 \%$ \\
\hline Grade IV & $4.9 \%$ & $4.9 \%$ & $32.1 \%$ \\
\hline Grade III-IV & $19.0 \%$ & $26.1 \%$ & \\
\hline 5 yrs $(n=165)$ & & & $11.5 \%$ \\
\hline Grade III & $19.4 \%$ & $20.0 \%$ & $38.8 \%$ \\
\hline Grade IV & $8.5 \%$ & $8.5 \%$ & \\
\hline Grade III-IV & $27.9 \%$ & $28.5 \%$ & $11.9 \%$ \\
\hline 7 yrs $(n=151)$ & & & $42.4 \%$ \\
\hline Grade III & $25.8 \%$ & $25.2 \%$ & \\
\hline Grade IV & $8.6 \%$ & $7.3 \%$ & \\
\hline Grade III-IV & $34.4 \%$ & $32.5 \%$ & $13.0 \%$ \\
\hline 10 yrs $(n=146)$ & & & $39.0 \%$ \\
\hline Grade III & $20.5 \%$ & $19.9 \%$ & \\
\hline Grade IV & $8.2 \%$ & $10.3 \%$ & \\
\hline Grade III-IV & $28.8 \%$ & $30.1 \%$ & \\
\hline
\end{tabular}

relation between $\mathrm{HO}$ grade and ROM. In the current study, while there were patients with reported grade III or IV HO and patients with reduced angular motion, these observations were not frequent enough to negatively influence the overall average angular motion at the index levels of CDA patients, which was maintained over time out to 10 years. By definition, grade III HO still allows a certain degree of motion and comprised a majority of the "severe" HO cases, perhaps accounting for this seeming discrepancy in findings. There is currently a separate study in preparation to examine in detail the relationship between $\mathrm{HO}$ grade and ROM (personal communication, Medtronic, Inc., 2019).

This clinical trial, like those of other FDA-approved CDA trials, was performed without treatment blinding, something not possible in this type of study. However, measures were taken to preclude bias: radiological assessments were made by independent reviewers, adverse events were evaluated by an independent committee, and statistical analyses at several of the follow-up intervals were confirmed by statisticians independent of the study sponsor. Patient bias in reporting subjective outcomes could have occurred, but it seems unlikely that any such bias in pain ratings or similar measures would persist over the 10-year study period. Patient satisfaction ratings did not differ between groups. The follow-up rates at 10 years were quite high for that lengthy of an interval and were similar between the groups $(86.0 \%$ for the CDA group and $84.9 \%$ for the ACDF group). In addition, results were consistent with those found for earlier intervals. Therefore, selection bias that would affect the comparison between groups was unlikely.

Although several other studies with follow-up between 5 and 10 years have been reported, this appears to be the first study to report results through 10 years postoperatively for an artificial disc replacement device used at two cervical levels, showing long-term maintenance of results with the Prestige LP and its continued superiority to ACDF over time.

\section{Conclusions}

The low-profile Prestige LP Cervical Disc, implanted at two adjacent levels in this study, was statistically noninferior to ACDF in every outcome measure and was statistically superior in overall success rate as well as NDI success rate, neurological success rate, and mean NDI and neck pain scores. Improved clinical outcomes and segmental motion were maintained through 10 years after surgery, with a significantly lower rate of implant- or implant/procedure-related serious adverse effects and statistically lower rates of secondary surgeries at both index levels and adjacent levels than ACDF. The Prestige LP Cervical Disc is an effective alternative to standard fusion treatment in patients with DDD associated with intractable radiculopathy or myelopathy at two adjacent levels of the cervical spine.

\section{Acknowledgments}

We would like to thank Karen I. Berliner, $\mathrm{PhD}$, who provided significant help with manuscript preparation and editing. We also acknowledge the large number of investigators who participated in the postapproval study and whose patients are included in this report. The study sponsor, Medtronic, provided statistical analysis reports, and Guorong Ma, $\mathrm{PhD}$, Senior Clinical Research Director at Medtronic, was made available to answer questions.

\section{References}

1. Badve SA, Nunley PD, Kurra S, Lavelle WF: Review of longterm outcomes of disc arthroplasty for symptomatic single level cervical degenerative disc disease. Expert Rev Med Devices 15:205-217, 2018

2. Bae HW, Kim KD, Nunley PD, Jackson RJ, Hisey MS, Davis RJ, et al: Comparison of clinical outcomes of 1- and 2-level total disc replacement: Four-year results from a prospective, randomized, controlled, multicenter IDE clinical trial. Spine (Phila Pa 1976) 40:759-766, 2015

3. Burkus JK, Haid RW, Traynelis VC, Mummaneni PV: Longterm clinical and radiographic outcomes of cervical disc replacement with the Prestige disc: results from a prospective randomized controlled clinical trial. J Neurosurg Spine 13:308-318, 2010

4. Burkus JK, Traynelis VC, Haid RW Jr, Mummaneni PV: Clinical and radiographic analysis of an artificial cervical disc: 7-year follow-up from the Prestige prospective randomized controlled clinical trial. Clinical article. J Neurosurg Spine 21:516-528, 2014

5. Cappelletto B, Giorgiutti F, Veltri C, Trevigne MA, Facchin P, Del Fabro P: Disc prosthesis replacement and interbody fusion in the treatment of degenerative cervical disc disease: comparative analysis of 176 consecutive cases. Eur Spine J 22 (6 Suppl 6):S894-S899, 2013

6. Chang UK, Kim DH, Lee MC, Willenberg R, Kim SH, Lim $\mathrm{J}$ : Changes in adjacent-level disc pressure and facet joint force after cervical arthroplasty compared with cervical discectomy and fusion. J Neurosurg Spine 7:33-39, 2007

7. Coric D, Guyer RD, Nunley PD, Musante D, Carmody C, Gordon C, et al: Prospective, randomized multicenter study of cervical arthroplasty versus anterior cervical discectomy and fusion: 5-year results with a metal-on-metal artificial disc. J Neurosurg Spine 28:252-261, 2018 
8. Davis RJ, Kim KD, Hisey MS, Hoffman GA, Bae HW, Gaede $\mathrm{SE}$, et al: Cervical total disc replacement with the Mobi-C cervical artificial disc compared with anterior discectomy and fusion for treatment of 2-level symptomatic degenerative disc disease: a prospective, randomized, controlled multicenter clinical trial: clinical article. J Neurosurg Spine 19:532-545, 2013

9. Dmitriev AE, Cunningham BW, Hu N, Sell G, Vigna F, McAfee PC: Adjacent level intradiscal pressure and segmental kinematics following a cervical total disc arthroplasty: an in vitro human cadaveric model. Spine (Phila Pa 1976) 30:1165-1172, 2005

10. Gornet MF, Burkus JK, Shaffrey ME, Argires PJ, Nian H, Harrell FE Jr: Cervical disc arthroplasty with PRESTIGE LP disc versus anterior cervical discectomy and fusion: a prospective, multicenter investigational device exemption study. J Neurosurg Spine 23:558-573, 2015

11. Gornet MF, Lanman TH, Burkus JK, Hodges SD, McConnell JR, Dryer RF, et al: Cervical disc arthroplasty with the Prestige LP disc versus anterior cervical discectomy and fusion, at 2 levels: results of a prospective, multicenter randomized controlled clinical trial at 24 months. J Neurosurg Spine 26:653-667, 2017

12. Heller JG, Sasso RC, Papadopoulos SM, Anderson PA, Fessler RG, Hacker RJ, et al: Comparison of BRYAN cervical disc arthroplasty with anterior cervical decompression and fusion: clinical and radiographic results of a randomized, controlled, clinical trial. Spine (Phila Pa 1976) 34:101-107, 2009

13. Jackson RJ, Davis RJ, Hoffman GA, Bae HW, Hisey MS, Kim KD, et al: Subsequent surgery rates after cervical total disc replacement using a Mobi-C Cervical Disc Prosthesis versus anterior cervical discectomy and fusion: a prospective randomized clinical trial with 5-year follow-up. J Neurosurg Spine 24:734-745, 2016

14. Koenig SA, Spetzger U: Clinical outcome of anterior cervical discectomy and fusion versus total disc replacement-a metaanalysis of 2532 cases. Insights Neurosurg 1:14, 2016

15. Lanman TH, Burkus JK, Dryer RG, Gornet MF, McConnell J, Hodges SD: Long-term clinical and radiographic outcomes of the Prestige LP artificial cervical disc replacement at 2 levels: results from a prospective randomized controlled clinical trial. J Neurosurg Spine 27:7-19, 2017

16. Lavelle WF, Riew KD, Levi AD, Florman JE: Ten-year outcomes of cervical disc replacement with the BRYAN Cervical Disc: results from a prospective, randomized, controlled clinical trial. Spine (Phila Pa 1976) 44:601-608, 2019

17. Lopez-Espina CG, Amirouche F, Havalad V: Multilevel cervical fusion and its effect on disc degeneration and osteophyte formation. Spine (Phila Pa 1976) 31:972-978, 2006

18. McDowell I: Measuring Health, A Guide to Rating Scales and Questionnaires. New York: Oxford University Press, 1996

19. Mehren C, Suchomel P, Grochulla F, Barsa P, Sourkova P, Hradil J, et al: Heterotopic ossification in total cervical artificial disc replacement. Spine (Phila Pa 1976) 31:2802-2806, 2006

20. Mummaneni PV, Burkus JK, Haid RW, Traynelis VC, Zdeblick TA: Clinical and radiographic analysis of cervical disc arthroplasty compared with allograft fusion: a randomized controlled clinical trial. J Neurosurg Spine 6:198-209, 2007

21. Murrey D, Janssen M, Delamarter R, Goldstein J, Zigler J, Tay B, et al: Results of the prospective, randomized, controlled multicenter Food and Drug Administration investigational device exemption study of the ProDisc-C total disc replacement versus anterior discectomy and fusion for the treatment of 1-level symptomatic cervical disc disease. Spine J 9:275-286, 2009

22. Nunley PD, Cavanaugh DA, Kerr EJ III, Utter PA, Campbell PG, Frank KA, et al: Heterotopic ossification after cervical total disc replacement at 7 years-prevalence, progression, clinical implications, and risk factors. Int J Spine Surg 12:352-361, 2018

23. Nunley PD, Coric D, Frank KA, Stone MB: Cervical disc arthroplasty: current evidence and real-world application. Neurosurgery 83:1087-1106, 2018

24. Radcliff K, Coric D, Albert T: Five-year clinical results of cervical total disc replacement compared with anterior discectomy and fusion for treatment of 2-level symptomatic degenerative disc disease: a prospective, randomized, controlled, multicenter investigational device exemption clinical trial. J Neurosurg Spine 25:213-224, 2016

25. Radcliff K, Davis RJ, Hisey MS, Nunley PD, Hoffman GA, Jackson RJ, et al: Long-term evaluation of cervical disc arthroplasty with the Mobi-C@C Cervical Disc: a randomized, prospective, multicenter clinical trial with seven-year followup. Int J Spine Surg 11:31, 2017

26. Robertson JT, Papadopoulos SM, Traynelis VC: Assessment of adjacent-segment disease in patients treated with cervical fusion or arthroplasty: a prospective 2-year study. J Neurosurg Spine 3:417-423, 2005

27. Shi R, Li J, Liu H, Ding C, Hu T, Li T, et al: Clinical comparison of 2 implantation systems for single-level cervical disk replacement. Orthopedics 37:e161-e168, 2014

28. Swank ML, Lowery GL, Bhat AL, McDonough RF: Anterior cervical allograft arthrodesis and instrumentation: multilevel interbody grafting or strut graft reconstruction. Eur Spine J 6:138-143, 1997

29. Vaccaro A, Beutler W, Peppelman W, Marzluff J, Mugglin A, Ramakrishnan PS, et al: Long-term clinical experience with selectively constrained SECURE-C cervical artificial disc for 1-level cervical disc disease: results from seven-year followup of a prospective, randomized, controlled investigational device exemption clinical trial. Int J Spine Surg 12:377-387, 2018

30. Veeravagu A, Cole T, Jiang B, Ratliff JK: Revision rates and complication incidence in single- and multilevel anterior cervical discectomy and fusion procedures: an administrative database study. Spine J 14:1125-1131, 2014

31. Vernon H, Mior S: The Neck Disability Index: a study of reliability and validity. J Manipulative Physiol Ther 14:409_ 415, 1991

32. Wang CS, Chang JH, Chang TS, Chen HY, Cheng CW: Loading effects of anterior cervical spine fusion on adjacent segments. Kaohsiung J Med Sci 28:586-594, 2012

33. Ware JE, Kosinski M, Keller SD: SF-36 Physical and Mental Health Summary Scales: A User's Manual, ed 2. Boston: The Health Institute, New England Medical Center, 1994

34. Wu TK, Wang BY, Meng Y, Ding C, Yang Y, Lou JG, et al: Multilevel cervical disc replacement versus multilevel anterior discectomy and fusion: a meta-analysis. Medicine (Baltimore) 96:e6503, 2017

35. Xiang W, Shi L, Jiang C, Tang Y, Jiang L: The effect of Mobi-C cervical total disc replacement versus ACDF in symptomatic degenerative disc disease: a meta-analysis of randomized controlled trials. Int J Clin Exp Med 11:29322939, 2018

36. Xu B, Ma JX, Tian JH, Ge L, Ma XL: Indirect meta-analysis comparing clinical outcomes of total cervical disc replacements with fusions for cervical degenerative disc disease. Sci Rep 7:1740, 2017

37. Xu S, Liang Y, Zhu Z, Qian Y, Liu H: Adjacent segment degeneration or disease after cervical total disc replacement: a meta-analysis of randomized controlled trials. J Orthop Surg Res 13:244, 2018

38. Zhang Y, Liang C, Tao Y, Zhou X, Li H, Li F, et al: Cervical total disc replacement is superior to anterior cervical decompression and fusion: a meta-analysis of prospective randomized controlled trials. PLoS One 10:e0117826, 2015 
39. Zhao H, Cheng L, Hou Y, Liu Y, Liu B, Mundra JJ, et al: Multi-level cervical disc arthroplasty (CDA) versus singlelevel CDA for the treatment of cervical disc diseases: a metaanalysis. Eur Spine J 24:101-112, 2015

\section{Disclosures}

The clinical trial was sponsored by Medtronic, Inc., Memphis, $\mathrm{TN}$; they provided access to the data and statistical analyses. The investigational device exemption and postapproval study was also sponsored by Medtronic, Memphis, TN. M. F. Gornet reports being a consultant for Aesculap and Medtronic; direct stock ownership in Bonovo, International Spine \& Orthopedic Institute, LLC, Nocimed, OuroBoros, and Paradigm Spine; and receiving royalties from Medtronic and RTI. T. H. Lanman reports being a consultant for Medtronic, NuVasive, and Stryker; receiving royalties from Stryker and Medtronic, and being a patent holder with Medtronic and Stryker. J. K. Burkus reports being a consultant for Medtronic and Zimmer-Biomet; receiving royalties from ZimmerBiomet; and receiving research support from Medtronic and NuVasive. R. F. Dryer reports being a consultant for and receiving royalties from NuVasive and Globus Medical. J. R. McConnell reports being a consultant for Globus Medical, DePuy/Synthes, and IMSE; receiving royalties from Globus Medical; direct stock ownership in Globus Medical; being on the speakers bureau for Globus Medical and Zimmer-Biomet; and being a patent holder with IMSE. S. D. Hodges reports being a consultant for Medtronic. F. W. Schranck reports direct stock ownership in Nocimed.

\section{Author Contributions}

Conception and design: Gornet. Acquisition of data: Gornet, Lanman, Burkus, Dryer, McConnell, Hodges. Analysis and interpretation of data: Gornet. Drafting the article: Gornet, Schranck. Critically revising the article: all authors. Reviewed submitted version of manuscript: all authors. Approved the final version of the manuscript on behalf of all authors: Gornet. Administrative/technical/ material support: Schranck. Study supervision: Schranck.

\section{Correspondence}

Matthew F. Gornet: The Orthopedic Center of St. Louis, St. Louis, MO.mfgspine@gmail.com. 